\title{
Cytokine regulation of apoptosis and Bcl-2 expression in lymphocytes of patients with systemic lupus erythematosus
}

\author{
WB Graninger*,1, CW Steiner ${ }^{1}$, MT Graninger ${ }^{1}$, M Aringer ${ }^{1}$ \\ and JS Smolen ${ }^{1}$ \\ ${ }^{1}$ Division of Rheumatology, Department of Internal Medicine III, University of \\ Vienna, Austria \\ * Corresponding author: WB Graninger, Postfach 37, A-1097 Vienna, Austria. \\ Tel and Fax: +43-1-40400-4360; E-mail: Winfried.Graninger@akh-wien.ac.at
}

Received 22.10.99; revised 12.4.00; accepted 23.5.00

Edited by M Piacentini

\begin{abstract}
Both faulty regulation of apoptosis and the inappropriate expression of several interleukins have been considered important defects of lymphocytes in the human autoimmune disease systemic lupus erythematosus (SLE). We therefore tested the in vitro effect of recombinant interleukin (IL-)-2, 4, 7, and 15 on peripheral blood mononuclear cells from patients with SLE and from healthy volunteers. Intracellular Bcl-2 and Bax expression was measured by fluorocytometry and the rate of apoptosis was determined by the TUNEL technique and propidium iodide staining. IL-2, IL-4, IL-7 and IL-15 led to a significant increase in $\mathrm{Bcl}-2$ and a reduction in cell death rates, which was even more pronounced in SLE. Bax levels remained unchanged. Interestingly, the high ex vivo Bcl-2 content of lymphocytes from some SLE patients was maintained after growth factor withdrawal. Anti-apoptotic cytokine signaling may significantly influence the deregulation of cell death in SLE lymphocytes. Cell Death and Differentiation (2000) 7, 966 972.
\end{abstract}

Keywords: systemic lupus erythematosus; Interleukin-2; Interleukin-7; Interleukin-15; Bcl-2; Bax

Abbreviations: SLE, systemic lupus erythematosus; IL-2, Interleukin-2; IL-7, Interleukin-7; IL-15, Interleukin-15

\section{Introduction}

Systemic lupus erythematosus (SLE) is a systemic autoimmune disease characterized by a broad array of variable clinical features, autoantibodies, and deranged cytokines. Because of findings in animal models leading to autoimmunity $^{1}$ and in spontaneous experimental autoimmunity, ${ }^{2,3}$ apoptosis rates and apoptosis-related proteins in SLE have been investigated by several groups. Two findings have emerged from these studies: (1) Bcl-2 protein is elevated in bone marrow cells and peripheral blood $T$ lymphocytes of patients with SLE; ${ }^{-7}$ and (2) In SLE, in vitro apoptosis rates are elevated, and presumably there are more apoptotic cells in the periphery. ${ }^{4,8-10}$ From these findings, two interrelated questions arise: How do the contradictory findings of an elevated antiapoptotic protein, Bcl-2, and an elevated programmed cell death rate match? And which factors influence either of these features in active lupus? Theoretically, the finding of elevated $\mathrm{Bcl}-2$ could be due to technical problems. In discordance with this argument (and in spite of some contradictory observations, ${ }^{11-13}$ however, the wealth of well-controlled data from our and other laboratories find a consistent elevation in active SLE as well as a significant correlation of the Bcl-2 content with measures of disease activity and therefore strongly speak against such an idea. 4-7,14 One could also hypothesize that, in addition to the upregulation of $\mathrm{Bcl}-2$, its counterpart Bax might be upregulated, too, leaving the Bcl-2/Bax ratio unchanged. Since Bax has indeed not been investigated thoroughly in SLE it was therefore studied as part of the present work.

Alternatively, additional factors, such as cytokines, could be responsible for the elevation of Bcl-2. Finally, one can also hypothesize that the in vitro apoptosis rate is mostly artefactual in the sense that it is due to withdrawal of survival factor in vitro. A number of cytokines are likely to influence the rate of programmed cell death. ${ }^{15-19}$ Thus, survival factors such as cytokines would elevate $\mathrm{Bcl}-2$ in vivo, but cells dependent on these cytokines would die at an increased rate when subjected to an environment without these survival factors.

We therefore decided to investigate the influence of human cytokines on the lymphocytes of SLE patients and compare them to those of healthy control individuals. In the present study, we will show that the elevated Bcl-2 is not balanced by an elevation of Bax and that the $\gamma$-chain cytokines IL-2, IL-4, IL-7, and IL-15 upregulate Bcl-2 in healthy controls to levels seen in active SLE. In lupus cells, however, these cytokines lead to further Bcl-2 upregulation, in some patients to an even higher degree than in the controls. Moreover, these cytokines also prevent the increased apoptosis occurring in vivo.

\section{Results}

\section{IL-2 and IL-4 induce Bcl-2 in healthy and lupus lymphocytes}

The addition of either recombinant human interleukin 2 (IL-2) or IL-4 for $72 \mathrm{~h}$ led to a significant rise of Bcl-2 in healthy control PBMC (Table 1). Indeed, control lymphocytes cultured in the presence of $\mathrm{IL}-2$ reached $\mathrm{Bcl}-2$ levels similar to those seen in SLE cells ex vivo (Figure 1). Within SLE cells, however, the already increased $\mathrm{Bcl}-2$ expression was even 
Table 1 Mean fluorescence intensities of Bcl-2 antibody in lymphocytes

\begin{tabular}{|c|c|c|c|c|c|}
\hline & Healt & $n=19)$ & & & \\
\hline & & & & & $P$ vs $\mathrm{HC}$ \\
\hline Ex vivo & $333 \pm 64$ & 0.0001 & $473 \pm 141$ & 0.05 & 0.0001 \\
\hline 72 h RPMI & $271 \pm 55$ & & $427 \pm 133$ & & 0.0001 \\
\hline 72 h IL-2 & $484 \pm 12$ & 0.00001 & $550 \pm 29$ & 0.0001 & 0.05 \\
\hline 72 h IL-4 & $421 \pm 82$ & 0.0001 & $591 \pm 109$ & 0.0001 & 0.001 \\
\hline
\end{tabular}
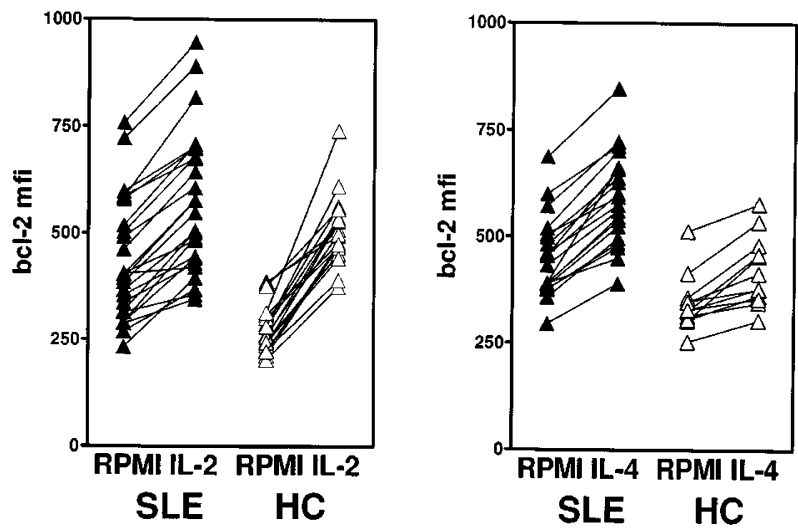

Figure 1 FACS analysis of intracellular $\mathrm{Bcl}-2$ in lymphocytes from SLE patients and healthy controls $(\mathrm{HC})$ after incubation for $72 \mathrm{~h}$ in serum free unsupplemented medium (RPMI) without or with interleukin-2 (IL-2) or interleukin-4 (IL-4). Results are expressed as mean fluorescence intensity (mfi)

further enhanced by IL-2 (Figure 1). Thus, in analogy to the Bcl-2 levels ex vivo, ${ }^{7}$ SLE cells expressed significantly higher levels of $\mathrm{Bcl}-2$ than controls after culture in medium supplemented with IL-2 or IL-4.

\section{IL-2 and IL-4 decrease lymphocyte programmed cell death in vitro}

At the same time, the addition of IL-2 or IL-4 significantly decreased the frequency of in vitro programmed cell death of SLE lymphocytes cultured in unsupplemented medium (Table 2). Under IL-2 stimulation, the lupus apoptosis rates were almost down to the rates of programmed cell death in control lymphocytes. However, some further reduction was also seen among control cells after interleukin- 2 or -4 supplementation. Nevertheless, neither in controls nor in SLE could IL-2 or IL-4 fully abrogate apoptosis under the culture conditions employed.

\section{IL-7 and IL-15, but not TNF- $\alpha$ exert effects similar to IL-2 on Bcl-2 expression and apoptosis}

In nine SLE patients, the effect of adding IL-2 or IL-7 or IL-15 to the culture medium for $24 \mathrm{~h}$ only was compared to resting culture conditions in unsupplemented medium alone. IL-7 and IL-15 had analogous effects on Bcl-2 expression and on the rate of apoptotic cells to those already described above for IL-2 in healthy volunteers as well as in SLE patients (Tables 3 and 4). Similar to IL-2, IL-7 and IL-15 also significantly reduced the frequency of apoptosis in lupus
PBMC of SLE (Table 4). Among cells from healthy controls, this reduction did not reach significance. Figure 3 shows the time kinetics of apoptosis in one representative SLE patient and in a control individual. The addition of TNF- $\alpha$ did not have any impact on in vitro apoptosis in this and five analogous experiments (data not shown). Interestingly, in this set of patients as well as in the total cohort studied here, there was an excellent correlation between clinical disease activity as measured by the ECLAM score and ex vivo Bcl-2 (not shown).

\section{$\mathrm{Bcl}-2$ decreases and apoptosis increases under resting conditions}

As shown in Figure 2, when PBMC were maintained in serumfree culture medium for $72 \mathrm{~h}$ ('resting culture'), the Bcl-2 content of viable lymphocytes decreased significantly both in SLE patients and in healthy controls. Group comparison (SLE vs controls) showed that SLE lymphocytes had a significantly higher $\mathrm{Bcl}-2$ content also after culture in serum free conditions (Table 1). This was in part due to a small subgroup of SLE patients whose lymphocyte $\mathrm{Bcl}-2$ content even increased after incubation in plain medium without any growth factors added (Figure 2). We could, however, not find any significant differences of these patients to the rest of the cohort with regard to their disease activity, organ manifestations, or autoantibodies. The lymphocytic Bcl-2 content was also elevated in freshly drawn blood of a small number of patients with septicemia $(n=5)$, but decreased swiftly after incubation in unsupplemented medium (not shown).

Intracellular Bax signal intensity was not different between patients and controls. Bax levels also did not change after in vivo culture with or without cytokines (not shown).

\section{Discussion}

SLE T cells are characterized by increased expression of the anti-apoptotic protein $\mathrm{Bcl}-2$ as well as increased propensity to undergo apoptosis. These observations are made persistently $^{5-9}$ (and the present study), although they appear contradictory. These two phenomena could be perceived as a consequence of preexisting $T$ cell activation, which occurs in vivo in SLE. ${ }^{20-23}$ Moreover, increased lymphocyte apoptosis occurs in diseases like viral infection or even in patients with severe burns. Elevated Bcl-2 is likewise found in the lymphocytes of patients with bacterial and viral infection and is thus by no means specific for autoimmune disease.

On the other hand, $\mathrm{Bcl}-2$ is not elevated in rheumatoid arthritis $\mathrm{PBMC}^{7}$ although rheumatoid arthritis 
Table 2 Per cent apoptotic cells (propidium iodide)

\begin{tabular}{|c|c|c|c|c|c|}
\hline & Health & $n=17$ ) & & & \\
\hline & & & & & $P$ vs $\mathrm{HC}$ \\
\hline Ex vivo & $0.4 \pm 0.2$ & 0.0001 & $1.7 \pm 1.6$ & 0.05 & 0.0001 \\
\hline 72 h RPMI & $6.7 \pm 2.9$ & & $12.3 \pm 8.5$ & & 0.01 \\
\hline 72 h IL-2 & $3.1 \pm 1.2$ & 0.0005 & $8.2 \pm 5.0$ & 0.0001 & 0.5 \\
\hline 72 h IL-4 & $5.1 \pm 3.4$ & 0.03 & $8.7 \pm 7.3$ & 0.0001 & 0.03 \\
\hline
\end{tabular}

Table 3 Mean fluorescence intensities of Bcl-2 antibody in lymphocytes

\begin{tabular}{|c|c|c|c|c|c|}
\hline & Healt & n=7) & & & $D$ мс НC \\
\hline Ex vivo & $294 \pm 52$ & 0.63 & $391 \pm 121$ & 0.14 & 0.11 \\
\hline 24 h RPMI & $277 \pm 31$ & & $333 \pm 63$ & & 0.08 \\
\hline 24 h IL-2 & $326+19$ & 0.043 & $379+87$ & 0.011 & 0.2 \\
\hline 24 h IL-7 & $361+33$ & 0.015 & $439+98$ & 0.0004 & 0.11 \\
\hline 24 h IL-15 & $324+32$ & 0.06 & $393+85$ & 0.0008 & 0.10 \\
\hline
\end{tabular}

Table 4 Per cent apoptotic cells (TUNEL)

\begin{tabular}{|c|c|c|c|c|c|}
\hline \multirow[b]{3}{*}{ Ex vivo } & \multirow{2}{*}{\multicolumn{2}{|c|}{$\begin{array}{c}\text { Healthy controls }(n=19) \\
\text { P vs RPMI }\end{array}$}} & \multicolumn{2}{|c|}{ SLE $(n=25)$} & \multirow[b]{2}{*}{$P$ vs HC } \\
\hline & & & & & \\
\hline & $2.1 \pm 3.0$ & 0.02 & $1.6 \pm 1.1$ & 0.002 & 0.65 \\
\hline 24 h RPMl & $11.3 \pm 10.5$ & & $19.3 \pm 12.1$ & & 0.18 \\
\hline 24 h IL-2 & $10.3+9.3$ & 0.33 & $11.0+7.8$ & 0.009 & 0.86 \\
\hline 24 h IL-7 & $9.2 \pm 8.4$ & 0.09 & $12.2 \pm 9.8$ & 0.02 & 0.52 \\
\hline 24 h IL-15 & $10.1 \pm 9.0$ & 0.36 & $10.6 \pm 11.5$ & 0.004 & 0.93 \\
\hline
\end{tabular}

also represents an autoimmune disease with considerable lymphocyte activation. In addition, double staining experiments with conventional activation markers such as CD25 or HLA-DR have repeatedly failed to allocate increased $\mathrm{Bcl}-2$ content or increased apoptosis to activated lymphocytes, although the data clearly showed that $\mathrm{T}$ lymphocytes are responsible for these phenomena $^{7}$ (and unpublished data). Therefore mechanisms other than conventional T-cell activation might be responsible for deregulating cell death in SLE. The deregulation of the cytokine network in $\operatorname{SLE}^{24,25}$ might well be operative in determining the observed deregulation of in vitro cell survival in this disease. ${ }^{10}$

In this study we show that SLE lymphocytes respond to the in vitro exposure to exogenous IL-2, 4, 7 and 15, all of which belong to a group of cytokines sharing a receptor element, the common $\gamma$-chain. Although the $\mathrm{Bcl}-$ 2 content of these cells is already significantly enhanced without cytokine addition, as compared to healthy controls, the increase in $\mathrm{Bcl}-2$ is even more pronounced after incubation with these cytokines. This overreaction to $\gamma$-chain interleukins may be of considerable importance. After all, these cytokines are known to allow for $\mathrm{T}$ cell activation and proliferation; they also prevent apoptosis induced by activation or deprivation of growth factors. 26-28 Lymphocytes with a tuned up survival state (as indicated by a high $\mathrm{Bcl}-2$ content) which even respond more strongly to anti-apoptotic cytokine signals could contribute a disease-perpetuating factor as indicated by experimental animal systems. ${ }^{29-33}$ Thus, defects of cell death signal transduction pathways in SLE might lead to the survival of autoreactive cells and to cell activation even without the expression of conventional activation markers. ${ }^{34,35}$ Since the anti-apoptotic cytokines used here share a common receptor element, the gamma chain which uses denominated intracellular signaling molecules, ${ }^{36}$ the study of cell death signal transduction and of Janus kinases or signal transducers (STATs) ${ }^{37,38}$ and their inhibitors ${ }^{39,40}$ is warranted in SLE.

At this point, we do not have a conclusive explanation for our finding, that among the SLE patients studied, the 'abnormal' increase in Bcl-2 persisted (and was sometimes even augmented) during $72 \mathrm{~h}$ of culture in medium devoid of exogenous growth factors (Figure 2). Our experimental conditions did, however, include the presence of other mononuclear cells during the 'resting' culture, so that ongoing cellular interactions or autocrine cytokine circuits cannot be excluded.

The observations made here, including the correlation of $\mathrm{Bcl}-2$ expression and cytokine-induced enhancement of $\mathrm{Bcl}-2$ expression, are compatible with a role of cytokineinduced anti-apoptotic events in the pathogenesis of SLE. Since synergistic effects of $\mathrm{Bcl}-2$ genotypes and cytokine abnormalities have been reported to predispose to disease expression, ${ }^{41,42}$ further dissection of the mechanisms and regulation of propriocidal and cytokine-induced cell death may lead to a better understanding of the pathogenesis of SLE. 


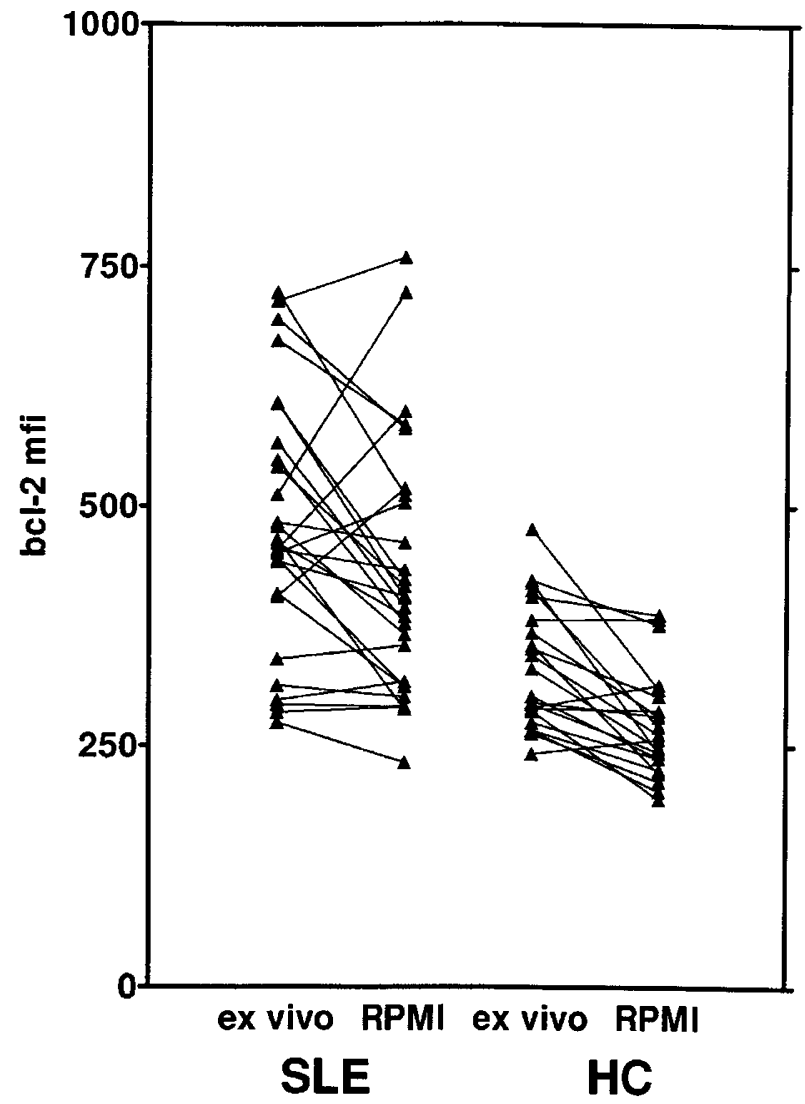

Figure 2 Cytofluorographic determination of intracellular Bcl-2 in lymphocytes from SLE patients and healthy controls $(\mathrm{HC})$ ex vivo or after incubation for $72 \mathrm{~h}$ in serum free unsupplemented medium (RPMI). Results are expressed as mean fluorescence intensity (mfi)

\section{Materials and Methods}

\section{Patients}

Forty consecutive outpatients (37 female, age $34 \pm 16.3$ years (mean \pm SD) fulfilling at least four ACR criteria for the classification of SLE gave informed consent to the use of their blood for this study. Disease duration was $6.5 \pm 6.2$ years, disease activity as measured by the ECLAM score ${ }^{43}$ was moderate to low $(2.8 \pm 1.6)$. Thirty-one patients were on low dose steroids (range 5 to $10 \mathrm{mg} /$ day), 17 were taking azathioprine in doses between 50 and $150 \mathrm{mg} /$ day, 14 patients had been prescribed $200 \mathrm{mg}$ of daily chloroquine and 15 were on steroids only without further immuno-modulatory medication. Statistical comparison of Bcl-2 signal and levels of apoptosis did not show any differences when the patient cohort was stratified according to different treatments. A subgroup of nine female patients and seven age-matched female controls without any medication was used for the experiments using IL-2, IL-7 and IL-15. Patients who had received intravenous cyclophosphamide within 6 weeks prior to this investigation or patients with clinical or laboratory signs of concurrent infectious disease were not included in this study. A convenience group of 39 healthy laboratory personnel (15 female, age $27 \pm 4.2$ ) served as a control population. While there was no equivalence in the age- and sex-matching of the controls and patients, large series of observations on $\mathrm{Bcl}-2$ levels or in vitro apoptosis did not show any influence of age or sex on these parameters (Stummvoll et al, submitted).
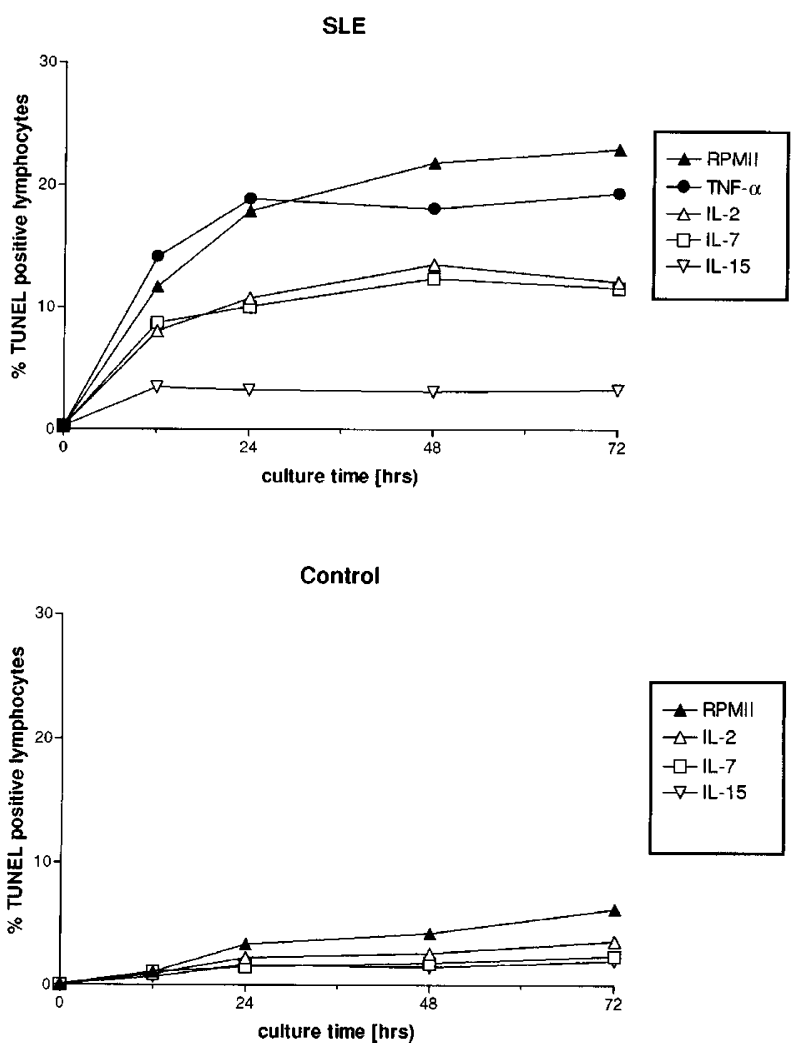

Figure 3 Representative examples for the time kinetics of apoptosis as determined by the TUNEL-reaction in a SLE patient and a healthy control. Cytokines added to the cultures are denoted in the insert, RPMI denotes medium devoid of any growth factors

\section{Blood cell purification and culture}

PBMC were isolated from heparinized blood using Ficoll-Paque density gradient centrifugation. Blood from at least one healthy volunteer was always processed in parallel with the patient samples. Isolation and staining of the cells was performed within 30-60 min after drawing the blood. Culture of cells was performed for 24 or $72 \mathrm{~h}$ under standard conditions in 96-well plates in RPMI 1640 without human or bovine calf serum in order to avoid any growth or death signals generated by exogenous biological sources ('resting medium'). Recombinant human (rh)-IL-2 (Biosource International, Camarillo, CA, USA), IL-4, IL-7, IL-15 (Pharma Biotechnologie, Hannover, Germany) or TNF- $\alpha$ (PBH, Hannover, Germany) was added to cell cultures in concentrations of 10 to $100 \mathrm{u} / \mathrm{ml}$.

After incubation in plastic wells, non-adherent cells were recovered by rinsing with medium, cell recovery varied from 58 to $77 \%$. The addition of the various cytokines did not lead to significant variances of recovery rates. Viability of all cells cultured for 24 and $72 \mathrm{~h}$ in RPMI with or without cytokine supplementation always exceeded 90 and $85 \%$, respectively, when tested by trypan blue exclusion and there was no significant effect on viability observed after addition of the different cytokines.

\section{Measurement of intracellular Bcl-2 and Bax protein}

PBMC were analyzed immediately after venipuncture and isolation or culture. Cells were fixed and permeabilized using the Fix\&Perm cell permeabilization kit (An der Grub Inc., Kaumberg, Austria). Intracellular staining ${ }^{7}$ was performed simultaneously during the 

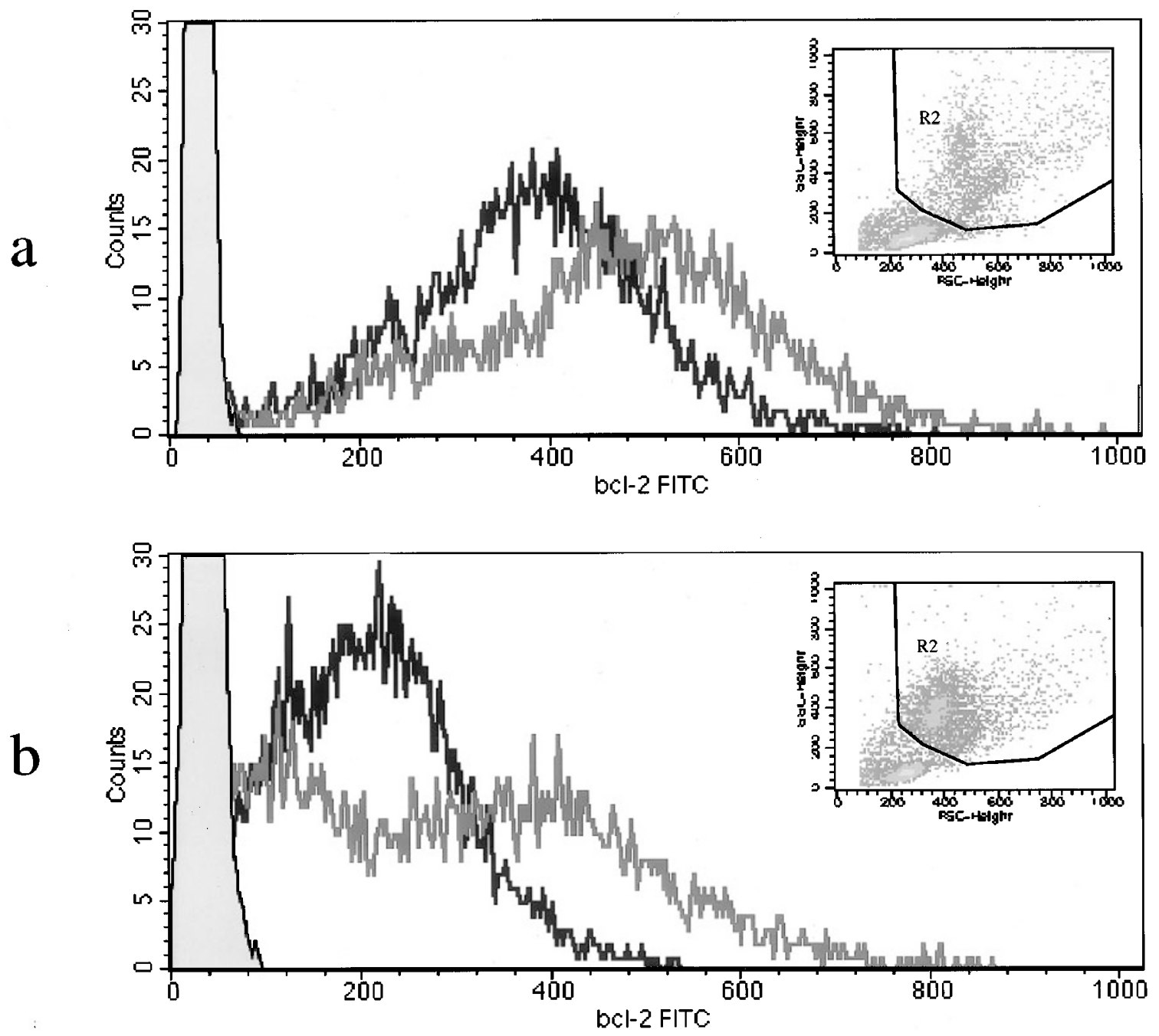

Figure 4 Intracellular staining of peripheral lymphocytes with a monoclonal Bcl-2 antibody. (a) Representative result from a SLE patient. The dark line shows the fluorescence intensity after $24 \mathrm{~h}$ of incubation in unsupplemented medium, the grey line depicts the result after incubation in identical medium plus human recombinant IL-2. (b) Result from a healthy control individual. Insert graph shows the gates set: the region R2 containing largely non-lymphocytic mononuclear cells is excluded from analysis

permeabilization step with the addition of fluorescein-(FITC)conjugated mouse-anti-Bcl-2 monoclonal antibody (DAKO A/S, Glostrup, Denmark) or Ig-isotype-matched control-antibody as well as with a polyclonal rabbit anti-bax antibody (Santa Cruz, CA, USA) and phycoerythrin (PE)-conjugated donkey anti-rabbit Fab2 fragment (Accurate Chemicals, New York, NY, USA). Cytofluorographic analyses were performed on a FACScan flow cytometer (BectonDickinson, Mountain View, CA, USA) with the acquisition gate excluding all cells but lymphocytes (e.g. see insert, Figure 4). Bcl-2fluorescence was recorded using linear signal-amplification. The instrument's settings were kept constant throughout the series of experiments, day-to-day variation of instrument parameters was tested by comparing the healthy controls analyzed in parallel with the patients' samples each day and was found to amount to a coefficient of variation of less than $10 \%$.

Previous double and triple staining experiments ${ }^{7}$ had shown that the abnormalities in Bcl-2 expression as well as in apoptosis were confined to the T lymphocytes, but there was no significant difference in $\mathrm{Bcl}-2$ expression or apoptosis between the different $\mathrm{T}$ lymphocyte subsets analyzed (CD4, CD8, CD4/8 double negative). Cells staining with CD25, HLA-DR, or CD45RO had shown decreased Bcl-2 signals. Since this was again seen in this study for unstimulated as well as for stimulated cells of SLE patients and controls, data of such subset analyses are not shown here.

\section{Detection of apoptosis}

The percentage of cells undergoing programmed cell death was measured in all cases by staining with propidium iodide in hypotonic citrate-buffer and analyzing the percentage of viable cells with a hypodiploid DNA content. In addition, 33 samples were tested also by the terminal deoxynucleotidyl-transferase (TdT) mediated dUTP nick end labeling technique (TUNEL) using the cytofluorimetric In-Situ Cell Death Detection Kit with fluorescein (Boehringer Mannheim, Mannheim, Germany). The percentage of FITC-fluorescing cellsreflecting apoptotic DNA fragmentation - was recorded using label mix 
without TdT as negative controls and PBMC incubated for $24 \mathrm{~h}$ with prednisolone as positive controls. For both methods, the analysis was performed by cytofluorometry as above, including both dying and viable lymphocytes into the acquisition gate, but excluding all cells of larger size and/or higher granularity. By determining the frequency of apoptotic cells with different methods, we saw an excellent correlation ( $r=0.89, P=0.0001$ ) between hypotonic propidium iodide staining and the TUNEL technique.

\section{Statistical analysis}

This included group comparison by the Mann-Whitney and Wilcoxon tests as well as Student's $t$-test (with Tukey-Kramer correction for multiple comparisons, when appropriate). Values are given as mean \pm SD. $P$-values $<0.05$ were considered significant.

\section{References}

1. Strasser A, Harris AW and Cory S (1991) bcl-2 transgene inhibits T cell death and perturbs thymic self-censorship. Cell 67: 889-899

2. Watanabe Fukunaga $R$, Brannan $\mathrm{Cl}$, Copeland NG, Jenkins NA and Nagata $S$ (1992) Lymphoproliferation disorder in mice explained by defects in Fas antigen that mediates apoptosis. Nature 356: $314-317$

3. Takahashi T, Tanaka M, Jenkins M, Copeland NG, Suda T and Nagata S (1994) Generalized lymphoproliferative disease in mice, caused by a point mutation in the fas ligand. Cell 76: 969-976

4. Lorenz HM, Grunke M, Hieronymus T, Herrmann M, Kuhnel A, Manger B and Kalden JR (1997) In vitro apoptosis and expression of apoptosis-related molecules in lymphocytes from patients with systemic lupus erythematosus and other autoimmune diseases. Arthritis Rheum. 40: 306-317

5. Ohsako S, Hara M, Harigai M, Fukasawa C and Kashiwazaki S (1994) Expression and function of Fas antigen and bcl-2 in human systemic lupus erythematosus Iymphocytes. Clin. Immunol. Immunopathol. 73: 109-114

6. Gatenby PA and Irvine M (1994) The bcl-2 proto-oncogene is overexpressed in systemic lupus erythematosus. J. Autoimmun. 7: 623-631

7. Aringer M, WintersbergerW, Steiner CW, Kiener H, Presterl E, Jaeger U, Smolen JS and Graninger WB (1994) High levels of bcl-2 protein in circulating T lymphocytes, but not B lymphocytes, of patients with systemic lupus erythematosus. Arthritis Rheum. 37: 1423-1430

8. Emlen W, Niebur J and Kadera R (1994) Accelerated in vitro apoptosis of lymphocytes from patients with systemic lupus erythematosus. J. Immunol. 152: 3685-3692

9. Perniok A, Wedekind F, Herrmann M, Specker C and Schneider M (1998) High levels of circulating early apoptotic peripheral blood mononuclear cells in systemic lupus erythematosus. Lupus 7: 113-118

10. Georgescu L, Vakkalanka RK, Elkon KB and Crow MK (1997) Interleukin-10 promotes activation-induced cell death of SLE lymphocytes mediated by Fas ligand. J. Clin. Invest. 100: 2622-2633

11. Chan EY, Ko SC and Lau CS (1997) Increased rate of apoptosis and decreased expression of bcl-2 protein in peripheral blood lymphocytes from patients with active systemic lupus erythematosus. Asian Pac. J. Allergy Immunol. 15: 3-7

12. Rose LM, Latchman DS and Isenberg DA (1997) Apoptosis in peripheral lymphocytes in systemic lupus erythematosus: a review. Br. J. Rheumatol. 36 : $158-163$

13. Rose LM, Latchman DS and Isenberg DA (1995) Bcl-2 expression is unaltered in unfractionated peripheral blood mononuclear cells in patients with systemic lupus erythematosus. Br. J. Rheumatol. 34: 316-320

14. Graninger WB (1992) Transcriptional overexpression of the proto-oncogene bcl2 in patients with systemic Lupus erythematosus. Wien. Klin. Wochenschr. 104: 205-207

15. Mor F and Cohen IR (1996) IL-2 rescues antigen-specific T cells from radiation or dexamethasone-induced apoptosis. Correlation with induction of Bcl-2. J. Immunol. 156: 515-522

16. Hernandez Caselles T, Martinez Esparza M, Sancho D, Rubio G and Aparicio $P$ (1995) Interleukin-7 rescues human activated T lymphocytes from apoptosis induced by glucocorticoesteroids and regulates bcl-2 and CD25 expression. Hum. Immunol. 43: 181-189
17. Broome HE, Dargan CM, Krajewski S and Reed JC (1995) Expression of Bcl-2, Bcl-x, and Bax after T cell activation and IL-2 withdrawal. J. Immunol. 155: 23112317

18. Armant M, Delespesse G and Sarfati M (1995) IL-2 and IL-7 but not IL-12 protect natural killer cells from death by apoptosis and up-regulate bcl-2 expression. Immunology 85: 331-337

19. Akbar AN, BorthwickNJ, Wickremasinghe RG, etal(1996) Interleukin-2 receptor common gamma-chain signaling cytokines regulate activated $\mathrm{T}$ cell apoptosis in response to growth factor withdrawal: selective induction of anti-apoptotic (bcl-2, bcl-xL) but not pro-apoptotic (bax, bcl-xS) gene expression. Eur. J. Immunol. 26: $294-299$

20. Portales Perez D, Gonzalez Amaro R, Abud Mendoza C and Sanchez Armass S (1997) Abnormalities in CD69 expression, cytosolic pH and Ca2+ during activation of lymphocytes from patients with systemic lupus erythematosus. Lupus 6: 48-56

21. Tokano Y, Morimoto S, Hishikawa T, Murashima A, Abe M, Sekigawa I, Takasaki Y, Hashimoto H, Okumura K, Shirai T and Hirose S (1997) Subsets of activated T cells in patients with systemic lupus erythematosus: the relation to cell cycle. Scand. J. Rheumatol. 26: 37-42

22. Spronk PE, Horst G, Van Der Gun BT, Limburg PC and Kallenberg CG (1996) Anti-dsDNA production coincides with concurrent $B$ and $T$ cell activation during development of active disease in systemic lupus erythematosus (SLE). Clin. Exp. Immunol. 104: 446-453

23. Chan EY, Lau CS and Zola H (1996) Expression of IL-2R, IL-4R, IL-6R on peripheral blood lymphocytes in systemic lupus erythematosus and correlation with disease activity: a prospective study. J. Clin. Pathol. 49:660-663

24. Crispin JC and Alcocer-Varela J (1998) Interleukin-2 and systemic lupus erythematosus - fifteen years later. Lupus 7: 214-222

25. Smolen JS, GraningerWB, Studnicka Benke Aand Steiner G (1997)Cytokines in systemic lupus erythematosus. In: Brennan FM, Feldmann M, eds. Cytokines and systemic autoimmunity. Austin: R.G. Landes Company; pp 137-152

26. Bulfone-Paus S, Ungureanu D, Pohl T, Lindner G, Paus R, Ruckert R, Krause H and Kunzendorf U (1997) Interleukin-15 protects from lethal apoptosis in vivo. Nat. Med. 3: $1124-1128$

27. Vella AT, Dow S, Potter TA, Kappler J and Marrack P (1998) Cytokine-induced survival of activated T cells in vitro and in vivo. Proc. Natl. Acad. Sci. U.S.A. 95: $3810-3815$

28. Lorenz HM, Hieronymus T, Grunke M, Manger B and Kalden JR (1997) Differential role for IL-2 and IL-15 in the inhibition of apoptosis in short-term activated human lymphocytes. Scand. J. Immunol. 45: 660-669

29. Lopez Hoyos M, Carrio R, Merino R, Buelta L, Izui S, Nunez G and Merino J (1996) Constitutive expression of bcl-2 in B cells causes a lethal form of lupuslike autoimmune disease after induction of neonatal tolerance to $\mathrm{H}-2 \mathrm{~b}$ alloantigens. J. Exp. Med. 183: 2523-2531

30. Reap EA, Felix NJ, Wolthusen PA, Kotzin BL, Cohen PL and Eisenberg RA (1995) bcl-2 transgenic Lpr mice show profound enhancement of lymphadenopathy. J. Immunol. 155: 5455-5462

31. Erb KJ, Ruger B, Von Brevern M, Ryffel B, Schimpl A and Rivett K (1997) Constitutive expression of interleukin (IL)-4 in vivo causes autoimmune-type disorders in mice. J. Exp. Med. 185: 329-339

32. Strasser A, Whittingham S, Vaux DL,Bath ML, Adams JM, Cory S and Harris AW (1991) Enforced BCL2 expression in B-lymphoid cells prolongs antibody responses and elicits autoimmune disease. Proc. Natl. Acad. Sci. USA 88 $8661-8665$

33. Alvarado C, Alarcon-Riquelme ME, Alcocer-Varela J and Fernandez C (1997) Participation of the $\mathrm{Bcl}-2$ and Fas molecules in experimental apoptosis of spleen B lymphocytes. Rev. Invest. Clin. 49: 171-178

34. Sakata K, Sakata A, Vela-Roch N, Espinosa R, Escalante A, Kong L, Nakabayashi T, Cheng J, Talal N and Dang H (1998) Fas (CD95)-transduced signal preferentially stimulates lupus peripheral T lymphocytes. Eur. J. Immunol. 28: $2648-2660$

35. Kovacs B, Liossis SN, Dennis GJ and Tsokos GC (1997) Increased expression of functional Fas-ligand in activated $T$ cells from patients with systemic lupus erythematosus. Autoimmunity 25: 213-221

36. Chen M, Cheng A, Chen YQ, Hymel A, Hanson EP, Kimmel L, Minami $Y$, Taniguchi T, Changelian PS and O'Shea JJ (1997) The amino terminus of JAK3 is necessary and sufficient for binding to the common gamma chain and confers the ability to transmit interleukin 2-mediated signals. Proc. Natl. Acad. Sci. USA 94: $6910-6915$ 
37. Pellegrini S and Dusanter FI (1997) The structure, regulation and function of the Janus kinases (JAKs) and the signal transducers and activators of transcription (STATs). Eur. J. Biochem. 248: 615-633

38. Darnell Jr JE (1997) STATs and gene regulation. Science 277: 1630-1635

39. Starr R and Hilton DJ (1998) SOCS: suppressors of cytokine signalling. Int. J. Biochem. Cell. Biol. 30: 1081-1085

40. Naka T, Matsumoto T, Narazaki M, Fujimoto M, Morita $Y$, Ohsawa $Y$, Saito $H$ Nagasawa T, Uchiyama $Y$ and Kishimoto T (1998) Accelerated apoptosis of lymphocytes by augmented induction of Bax in SSI-1 (STAT-induced STAT inhibitor-1) deficient mice. Proc. Natl. Acad. Sci. USA 95: 15577-15582

41. Komaki S, Kohno M, Matsuura N,Shimadzu M, Adachi N, Hoshide R, Nishiyama S and Matsuda I (1998) The polymorphic 43Thr bcl-2 protein confers relative resistance to autoimmunity: an analytical evaluation. Hum. Genet. 103: 435440
42. Mehrian R, Quismorio FP, Strassmann G, Stimmler MM, Horwitz DA, Kitridou RC, Gauderman WJ, Morrison J, Brautbar C and Jacob CO (1998) Synergistic effect between IL-10 and bcl-2 genotypes in determining susceptibility to systemic lupus erythematosus. Arthritis Rheum. 41: 596-602

43. Bombardieri S, Vitali C, Caponi L, Manca L and Bencivelli W (1994) Activity criteria in systemic lupus erythematosus. Clin. Exp. Rheumatol. 12 (Suppl 11): S45-S48 